\title{
Attitudes towards psychopharmacology and psychotherapy in psychiatric patients with and without migration background
}

\author{
Eva J. Brandl ${ }^{1,2^{*}{ }^{+}}$, Nora Dietrich ${ }^{1,2+}$, Nicoleta Mell ${ }^{1,2}$, Johanna G. Winkler ${ }^{1,2}$, Stefan Gutwinski ${ }^{1,2}$, \\ H. Joachim Bretz ${ }^{1,2}$ and Meryam Schouler-Ocak ${ }^{1,2}$
}

\begin{abstract}
Background: Sociodemographic factors, attitude towards treatment and acculturation may be important factors influencing the decision of immigrants to seek and maintain psychiatric treatment. A better understanding of these factors may significantly improve treatment adherence and outcome in these patients. Therefore, we investigated factors associated the attitude towards psychotherapy and medication in a sample of psychiatric outpatients with and without migration background.

Methods: $N=381$ patients in a psychiatric outpatient unit offering specialized treatment for migrants were included in this study. Attitude towards psychotherapy was assessed using the Questionnaire on Attitudes Toward Psychotherapeutic Treatment, attitude towards medication with the Drug Attitude Inventory-10. Acculturation, symptom load and sociodemographic variables were assessed in a general questionnaire. Statistical analyses included analyses of covariance and hierarchical regression.

Results: Patients of Turkish and Eastern European origin reported a significantly more positive attitude towards medication than patients without migration background. When controlling for sociodemographic and clinical variables, we did not observe any significant differences in attitude towards psychotherapy. Acculturation neither influenced the attitude towards psychotherapy nor towards medication.

Conclusion: Our study indicates that sociodemographic and clinical factors may be more relevant for patients' attitudes towards treatment than acculturation. Considering these factors in psychiatric treatment of patients with migration background may improve treatment outcome and adherence.
\end{abstract}

Keywords: Migrants, Attitude, Medication, Psychotherapy

\footnotetext{
* Correspondence: eva.brandl@charite.de

${ }^{\dagger}$ Eva J. Brandl and Nora Dietrich contributed equally to this work.

${ }^{1}$ Charité Universitätsmedizin Berlin, corporate member of Freie Universität Berlin, Humboldt-Universität zu Berlin, and Berlin Institute of Health, Department of Psychiatry and Psychotherapy, Campus Mitte, Berlin, Germany

Charité Universitätsmedizin Berlin, Berlin, Germany

${ }^{2}$ Psychiatrische Universitätsklinik der Charité im St. Hedwig Krankenhaus,

Große Hamburger Str. 5-11, 10115 Berlin, Germany
}

(c) The Author(s). 2020 Open Access This article is licensed under a Creative Commons Attribution 4.0 International License, which permits use, sharing, adaptation, distribution and reproduction in any medium or format, as long as you give appropriate credit to the original author(s) and the source, provide a link to the Creative Commons licence, and indicate if changes were made. The images or other third party material in this article are included in the article's Creative Commons licence, unless indicated otherwise in a credit line to the material. If material is not included in the article's Creative Commons licence and your intended use is not permitted by statutory regulation or exceeds the permitted use, you will need to obtain permission directly from the copyright holder. To view a copy of this licence, visit http://creativecommons.org/licenses/by/4.0/ The Creative Commons Public Domain Dedication waiver (http://creativecommons.org/publicdomain/zero/1.0/) applies to the data made available in this article, unless otherwise stated in a credit line to the data. 


\section{Background}

With rising numbers of migrants and refugees over the past years, there has been increasing interest in mental health issues of these groups. A variety of psychosocial risk factors, including lower socioeconomic status, higher risk for unemployment [1], discrimination [2] and experience of violence as well as migration stress [3] contribute to higher rates of psychiatric disorders in migrant populations. Although the risk for specific psychiatric disorders varies depending on the region of origin [3] as well as on the circumstances of being a migrant or a refugee [4], generally a higher prevalence of most psychiatric disorders has been reported [5-12]. Despite this increased risk and a higher symptom load compared to individuals without migration background [13-15], migrants tend to use mental health services, including psychotherapy, less often [16-19]. In addition, treatment adherence to psychopharmacological treatment has been reported to be lower in migrants and ethnic minorities [20-24]. Insufficient consideration of sociodemographic differences between migrants and non-migrants seeking treatment $[15,25]$ in clinical practice as well as relevant language and cultural barriers provide partial explanations for these issues. Another important, yet insufficiently investigated factor influencing treatment seeking and adherence is the attitude towards psychiatric and psychotherapeutic treatment in migrants. A negative attitude towards psychotherapy may be one of the main reasons not to seek treatment [26]. Only few studies on attitude towards psychotherapy in migrants have been performed to date, and most of these have been conducted in the United States, indicating a generally less positive attitude towards psychotherapy in migrants. A high impact of sociodemographic and symptom-related factors on the attitude has been reported [27]. Acculturation of migrants has also been identified as a factor influencing attitude towards psychotherapy [28-30]. However, a recent meta-analysis found ethnic differences in the impact of acculturation on attitudes towards psychological treatment with little impact in most ethnic groups except for individuals of Asian heritage [31]. Literature on the attitude towards psychotherapy in migrant populations in Germany and Europe is sparse but also indicates a less positive attitude in these groups [32-35]. However, the influence of acculturation on attitude towards psychotherapy of migrants in Germany has not been investigated extensively yet. Education, age, sex, (e.g., [27, 36, 37]) as well as psychiatric symptom load (e.g., [36, 38, 39]) have been investigated regarding an influence on attitude towards psychotherapy with heterogeneous results, indicating a need for further studies in this field.

Attitude towards medication has been shown to be an important predictor of medication adherence, e.g. [40-
42]. The attitude towards pharmacological treatment in migrants and ethnic minorities has only been examined in a few studies. Similar to the attitude towards psychotherapy, a less positive attitude towards medication has been found in ethnic minority patients [43-48].

The influence of acculturation on medication adherence in patients with mental disorders has not been investigated extensively, but better adherence in individuals with stronger orientation towards the host culture has been reported [49, 50]. However, acculturation was not associated with attitude towards medication in all studies [51]. In other medical areas, acculturation has been associated with better drug adherence, e.g. [49, 52-54]. To the best of our knowledge, there are no data on the influence of acculturation of attitude towards medication in psychiatric patients with migration background in Germany.

In summary, attitude towards psychotherapy and medication may influence treatment adherence and outcome. However, the specific relevance of factors potentially influencing these attitudes towards treatment, including clinical and sociodemographic factors, migration background and acculturation in migrants is not well understood yet. Therefore, we set out to a) examine the attitude of psychiatric patients with and without migration background towards psychotherapy as well as towards medication and b) to identify the association of relevant sociodemographic and clinical factors and acculturation with the attitudes towards psychotherapy and medication.

\section{Methods \\ Participants}

All patients treated in the outpatient unit of the Psychiatric University Hospital of Charité at St.Hedwig-Hospital in Berlin, Germany, between April and June 2015 and who did not fulfill our exclusion criteria (acute psychosis, severe cognitive impairment, acute emergency treatment) were invited to fill out a questionnaire provided in seven languages (German, English, French, Arabic, Farsi, Turkish and Russian). The outpatient unit offers general psychiatric outpatient treatment to two large downtown districts of Berlin and additionally is specialized in treatment of patients with migration background.

Questionnaires were handed out to the patients who came to their appointments in the outpatient unit and filled out in the waiting area after informed consent was obtained. Information on current medication and diagnoses according to ICD-10 criteria was obtained from electronic medical records. The study was approved by the ethics board of Charité - Universitätsmedizin Berlin and conducted in accordance with the Declaration of 
Helsinki. All participants gave written informed consent before participation in the study.

\section{Measures}

The questionnaire contained a general part with demographic and clinical data (such as marital status, duration of illness, employment status etc.). Current symptom load was assessed with the Symptom Checklist 14 (SCL14), a short version of the Symptom Checklist 90 [55]. These general characteristics of the sample have been described previously [15]. The SCL-14 subscales reached Cronbach's alpha of $\alpha=0.89$ for somatization, $\alpha=0.83$ for anxiety and $\alpha=0.87$ for depression in our dataset. For the purpose of this study, only patients without migration background and the largest migrant groups (Turkish, Eastern European, middle Eastern/north African (MENA [56];) plus Afghanistan/Pakistan (MENAP)) migration background) were included since the other groups were too small for meaningful analyses.

\section{Attitude towards psychotherapy}

Attitude towards psychotherapy was assessed using the Questionnaire on Attitudes Toward Psychotherapeutic Treatment (QAPT [36]) which consists of 20 statements rated on a Likert-type scale ranging from 1 ("I do not agree") to 4 ("I agree"). Four subscales are created to assess the attitude towards psychotherapy: psychotherapist's competence, anticipated judgment by others, general attitude towards psychotherapy and personal acceptance. Higher scores indicate a more positive attitude toward psychotherapy. The validity of the instrument was confirmed in the original publication of the questionnaire. The internal consistency of the subscales has been confirmed in the original publication [36]. In our own data set, the QAPT subscales reached the following $\alpha$-values: competence: $\alpha=0.52$, judgment: $\alpha=0.64$, general attitude: $\alpha=0.58$, acceptance: $\alpha=0.61$. The QAPT has been used in other cross-cultural studies on attitude towards psychotherapy before with higher $\alpha$-values for the QAPT subscales in some studies $[35,57]$ and comparable $\alpha$-values to our sample in others [34].

\section{Attitude towards medication}

To examine attitudes towards and subjective experience with medication, we applied the 10 -item version of the Drug Attitude Inventory (DAI [58]). The scale consists of ten statements (for example: "For me, the good things about medication outweigh the bad"; "I feel more normal on medication"; "It is ununatural for my mind and body to be controlled by medication") with a dichotomous response option (true/ false) and assesses general attitude towards medication. Several studies have underlined the validity and reliability of the DAI [59]. Cronbach's $\alpha$ of the DAI in our dataset was 0.68 .

\section{Acculturation}

In patients with migration background (defined as not holding German citizenship per birth, having immigrated to Germany and/or having at least one parent not holding German citizenship following the definition of the Federal Statistical Office [1]), acculturation was assessed using the Acculturation Index by Ward \& Rana-Deuba [60]. Based on a two-dimensional approach to acculturation it contains two subscales: "host national identification" and "co-national identification". Both scales range between 1 and 7 with higher values indicating a stronger identification with that culture. A high reliability (co-national identification scale $\alpha=.93$ and host identification scale $\alpha=.96$ ) and good validity of the Acculturation Index has previously been reported [61] with the same $\alpha$-values being obtained in our own dataset .

\section{Statistical analyses}

Data were analyzed using RStudio 0.99 .489 for Windows. Differences between the included migrant groups and patients without migration background in sociodemographic and clinical parameters were explored with analysis of variance (ANOVA), Chi-Quadrat-tests and Fisher-Yates-tests, respectively.

Analyses of covariance (ANCOVA) were conducted in order to assess if the subsamples with migration background differed on the five dimensions (four QAPT scales and DAI) from the subsample without migration background. Potentially relevant covariates (SCL-14 subscale values for anxiety, somatization and depression; age; education; gender; religious affiliation; medication intake; psychiatric inpatient stays) were theoretically derived, e.g. [27, 30]. Only those covariates that showed a significant correlation with the respective dependent variable (QAPT subscales and DAI) were included in the final analyses and are provided for each analysis in Table 2. Two ANCOVA were conducted per dimension. Due to the gender distribution differences in our subsamples, the first analysis included only gender as covariate in case it correlated with the dependent variable. The second analysis also included further sociodemographic (e.g. education, religious affiliation) and clinical factors (e.g. symptom severity, inpatient stays, medication intake). The adjusted means were compared with the Dunnett-test using the sample without migration background as control.

Hierarchical regressions were conducted to test if acculturation predicts a significant additional amount of variance in the samples with migration background after accounting for sociodemographic and clinical variables. The covariates from the prior analysis were adopted for each dependent variable. In the second step both scales of the Acculturation Index were added. Due to the exploratory character of the analyses, we did not correct $p$ - 
values for multiple testing. Patients who had returned questionnaires with more than $20 \%$ of missing values were excluded from the analyses. In the total sample, $6.6 \%$ of values were missing. We applied listwise deletion to missing values for the ANCOVA and the hierarchical regression to avoid a high loss of information.

\section{Results}

\section{Sociodemographic data}

The original sample comprised $N=423$ participants who had returned completed questionnaires out of $N=700$ patients who were invited to participate in the study response rate of $60.5 \%$ [15]. Due to the limited sample sizes, patients from Asia $(N=5)$, Africa $(N=10)$ Western Europe and America $(N=19)$ were not included in the analyses. $N=8$ patients had to be excluded due to incomplete questionnaires, resulting in a total sample of $N=381$ individuals. The sample included patients without migration background $(N=194)$, and patients of Turkish $(N=111)$, Eastern European $(N=39)$ or MENAP $(N=37)$ background. We found significant differences in terms of gender, education, religiousness, medication intake and diagnoses among the subsamples (see Table 1 ) as previously described for the overall sample [15]. There were also significant differences in reported symptom severity regarding somatic and anxiety symptoms. Due to the observed differences, sociodemographic and clinical variables were incorporated in the following statistical analyses as covariates.

\section{Attitudes toward psychotherapy and medication}

First, we analyzed whether patients with Turkish, Eastern European and MENAP background differed significantly in their attitude towards psychotherapy as measured by the four scales of the QAPT and in their attitude towards medication measured by the DAI as compared to patients without migration background. Two ANCOVA were conducted per QAPT scale and DAI. In the first ANCOVA, we only controlled for gender if necessary. In the second ANCOVA, we also added further relevant sociodemographic and clinical control variables. Sociodemographic and clinical variables with significant association with at least one of the QAPT subscales were education, number of inpatient stays in the history, current symptom load on the SCL subscales somatization and depression.

The mean value of the QAPT-judgment scale was significantly lower among the samples with East European and MENAP background compared to the sample without migration background, indicating a less positive attitude on this subscale of the QAPT (see Supplementary Table S1). However, after controlling for sociodemographic variables, no significant differences remained. On the QAPT scales competence, acceptance and general attitudes, the samples with Eastern European, Turkish and MENAP background did not differ significantly from the sample without migration background in both analyses (see Supplementary Tables S2-S4).

Regarding the attitude towards medication, patients with Turkish and Eastern European background had a significantly more positive attitude compared to the sample without migration background. This remained significant after controlling for potentially relevant sociodemographic and clinical variables (see Supplementary Table S5). There was no statistically significant difference in attitude towards medication between the MENAP-subgroup and patients without migration background.

\section{Acculturation and attitudes}

In the next step, we examined if acculturation explained an additional amount of variance beyond the identified relevant sociodemographic and clinical variables. We conducted a hierarchical regression with the two scales of the acculturation index (host national identification and co-national identification) added in the second step. The main results are presented in Table 2 (for further details, see Supplementary Table S6). The first $p$-value indicates if the model explains a significant amount of variance as compared to a null model. The second $\mathrm{p}$ value indicates whether the second model including the acculturation index (step 2) explains significantly more variance than the model without the acculturation index (step 1). For reasons of simplicity only the test statistics of the additional variables are presented in the table. The F-tests for $\Delta R^{2}$ did not reach significance (with one exception in the East European sample on the QAPTjudgment scale). Hence, the models including the acculturation indexes (apart from one exception) did not explain significantly more variance than the models without the acculturation indexes, indicating no major association of acculturation with the attitude towards psychotherapy as well as towards medication in our sample.

\section{Discussion}

To the best of our knowledge, this is the first study to investigate attitude towards psychotherapy and medication in a sample of patients with and without migration background in a psychiatric outpatient unit. We did not find major differences in the attitude towards psychotherapy after controlling for relevant sociodemographic and clinical factors. The attitude towards medication was more positive in patients with Turkish and Eastern European background. Acculturation did not have a significant association with patients' attitudes towards treatment in our sample except for the QAPT-judgment scale in the Eastern European subsample. In this 


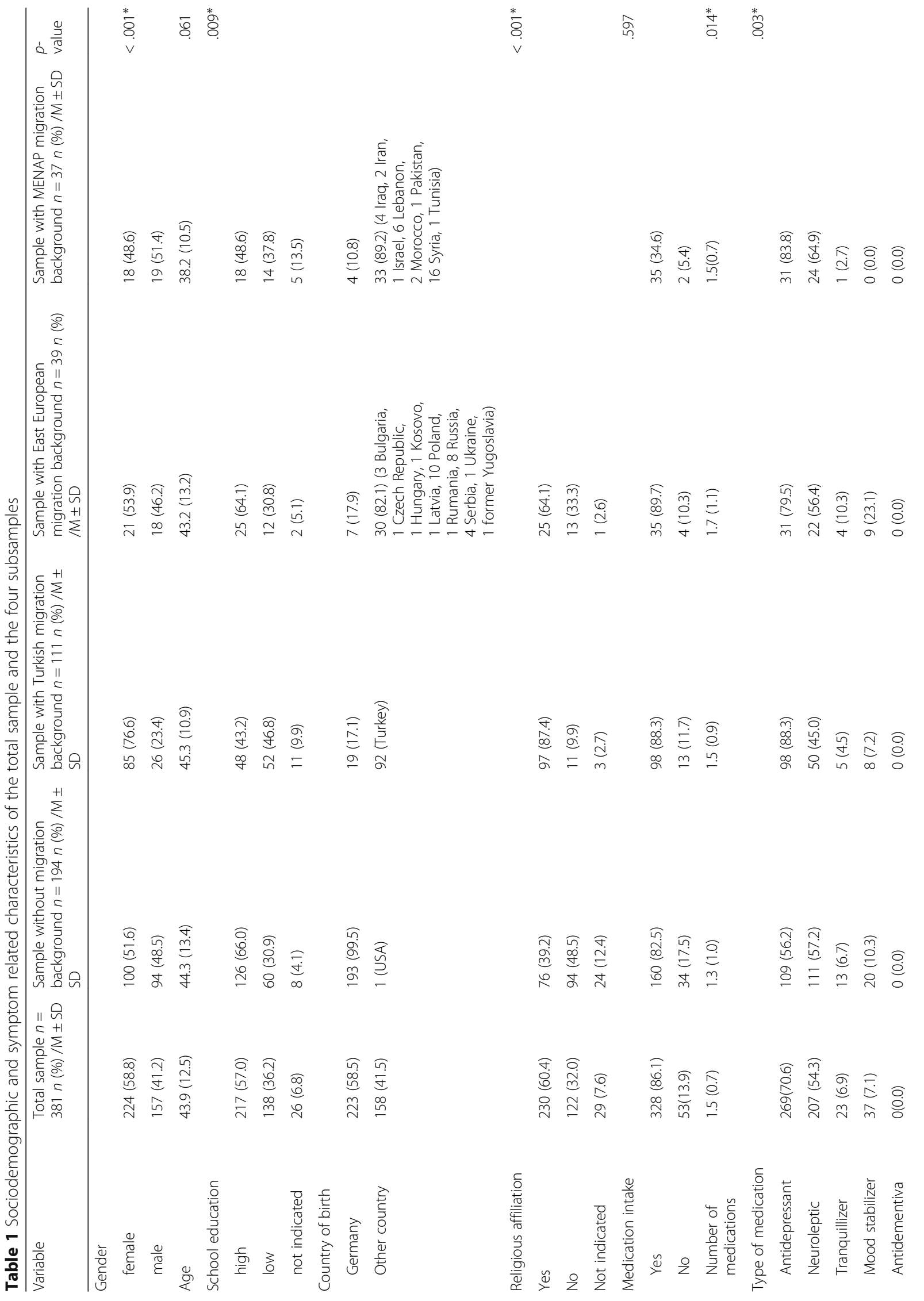




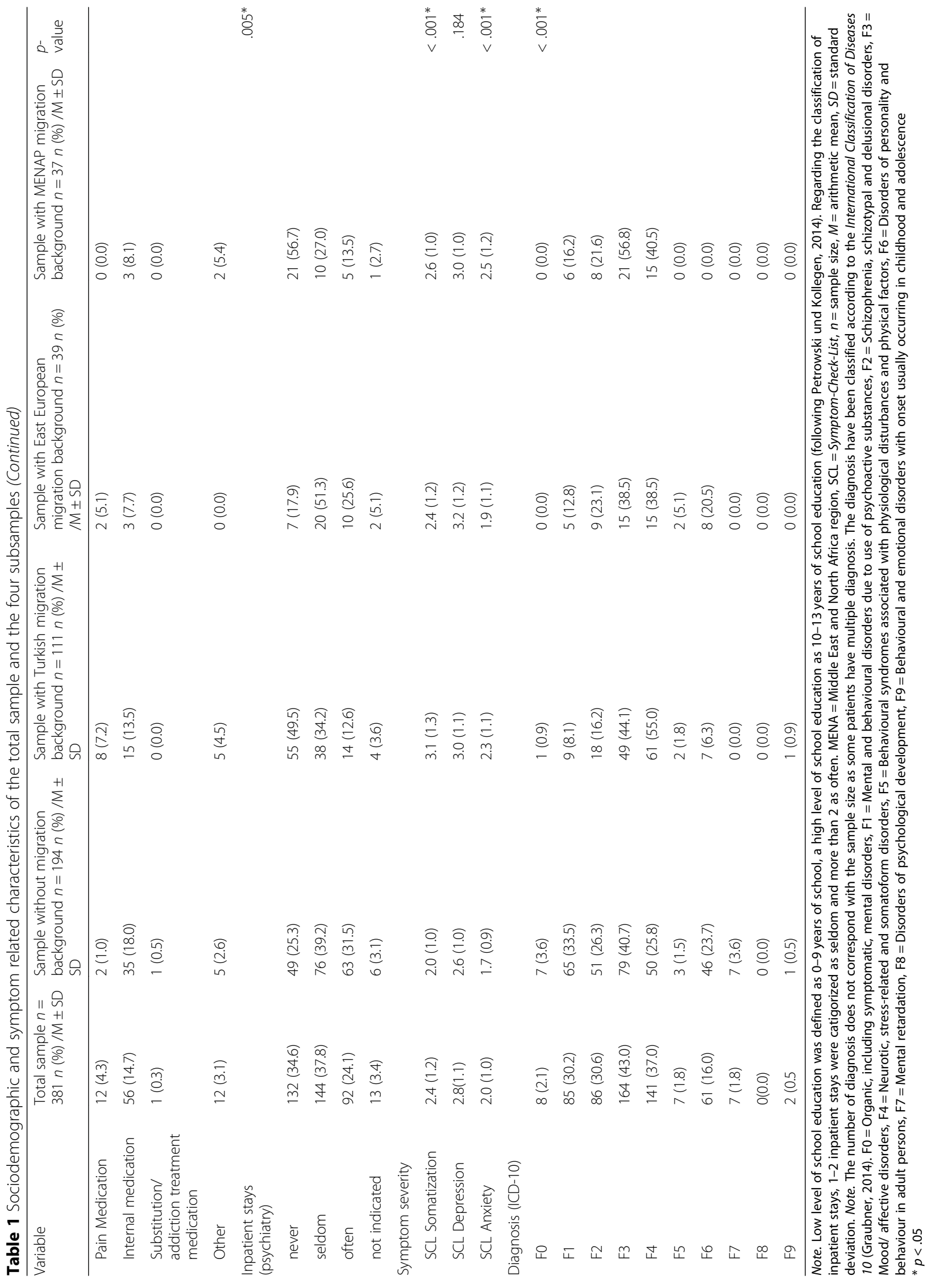


Table 2 Association of acculturation with attitude towards psychotherapy and medication

\begin{tabular}{|c|c|c|c|c|c|c|c|c|c|c|c|c|c|c|}
\hline \multirow[b]{2}{*}{ Dependent Variable } & \multicolumn{4}{|c|}{ Turkish background $(N=111)$} & \multirow[b]{2}{*}{$n$} & \multicolumn{4}{|c|}{ Eastern European background $(N=39)$} & \multirow[b]{2}{*}{$n$} & \multicolumn{4}{|c|}{ MENAP background $(N=37)$} \\
\hline & $\overline{R^{2}}$ & $\Delta R^{2}$ & $F$ for $\Delta R^{2}$ & $p$ for $\Delta R^{2}$ & & $\overline{R^{2}}$ & $\Delta R^{2}$ & $F$ for $\Delta R^{2}$ & $p$ for $\Delta R^{2}$ & & $\overline{R^{2}}$ & $\Delta R^{2}$ & $F$ for $\Delta R^{2}$ & $p$ for $\Delta R^{2} \quad r$ \\
\hline \multicolumn{15}{|l|}{ QUAPT judgment } \\
\hline Step 1: & $.17^{*}$ & .17 & 3.83 & $.003^{*}$ & & .27 & .27 & 1.66 & .186 & & .16 & .16 & 0.86 & .523 \\
\hline Step 2: & $.20^{*}$ & .03 & 1.91 & .154 & & .50 & .23 & 4.61 & $.022^{*}$ & & .19 & .03 & 0.42 & .662 \\
\hline \multicolumn{15}{|l|}{ Host national identification } \\
\hline Co-national identification & & & & & & & & & & & & & & \\
\hline
\end{tabular}

\section{QUAPT competence}

\begin{tabular}{|c|c|c|c|c|c|c|c|c|c|c|c|}
\hline Step 1: & .03 & .03 & 1.36 & .263 & .12 & .12 & 1.50 & .244 & .07 & .07 & 1.07 \\
\hline Step 2: & .06 & .03 & 1.17 & .315 & .23 & .11 & 1.54 & .237 & .07 & .00 & 0.01 \\
\hline
\end{tabular}

Host national identification

Co-national identification

\section{QUAPT-acceptance}

$\begin{array}{lllllllllllll}\text { Step 1: } & .07 & .07 & 3.09 & .051 & .35^{*} & .35 & 6.10 & .008^{*} & .01 & .01 & 0.11 & .897 \\ \text { Step 2: } & .12^{*} & .05 & 2.56 & .083 & .39^{*} & .04 & .76 & .480 & .04 & .03 & 0.42 & .663\end{array}$

Host national identification

Co- national Identification

\section{QUAPT general attitude}

Step 1:
Step 2:
Host national identification
Co-national identification

\begin{tabular}{|c|c|c|}
\hline $19 *$ & 3.12 & $.008^{*}$ \\
\hline $19^{*} .00$ & 0.34 & .715 \\
\hline
\end{tabular}

$\begin{array}{lll}.47^{*} & .47 & 2.71 \\ .51 & .04 & 0.51\end{array}$

$.047^{*}$

$\begin{array}{lll}.02 & .02 \quad 0.07\end{array}$

.998

$\begin{array}{llll}.10 & .08 & 0.81 & .459\end{array}$

Host national identification

\section{Drug Attitude Inventory}

Step 1:
Step 2:
Host national identification
2003Co-national identification

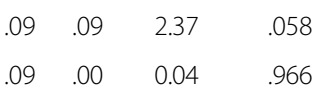

$\begin{array}{lll}.28 & .28 & 2.24 \\ .34 & .06 & 0.87\end{array}$

.096
.432

$\begin{array}{llll}.19 & .19 & 1.57 & .212 \\ .20 & .02 & 0.14 & .871\end{array}$

Main results of the hierarchical regression predicting the QUAPT scales judgment, competence, acceptance and general attitude as well as the DAI scale in the samples with Turkish, East European and MENAP background. The association of control variables with attitude towards psychotherapy and medication are included in Step 1. Acculturation scales are added to the other variates in the second step. For simplicity reasons, the control variables as well as the B- and $\beta$ values are not shown in this Table, details can be found in Supplementary Table S6. MENA = Middle East and North Africa Region, QUAPT = Questionnaire on Attitudes Toward Psychotherapeutic Treatment, DAI = Drug Attitude Inventory ${ }^{*} p<.05$

subsample, a higher level of acculturation was associated with a more positive attitude towards psychotherapy regarding anticipated judgment by others. However, due to the very limited sample size of this subsample and the low Cronbach's $\alpha$ of the QAPT-judgment scale, this finding needs to be considered with caution. Since this association was not observed in the two other subsamples with MENAP- and Turkish background, we do not assume a major impact of acculturation on anticipated judgement for utilizing psychotherapy by others; however, a replication in a larger sample would be required before final conclusions can be drawn.

These findings are partially in line with results of previous studies. Calliess et al. [32] also did not report an impact of acculturation on the attitude towards psychotherapy in young adult individuals with Turkish background in Germany. However, they found a significant influence of migration background on the attitude towards psychotherapy after controlling for sociodemographic variables, whereas these differences did not 
remain significant after controlling for confounders in our sample. In most ethnic groups, a recent metaanalysis did not report a major impact of acculturation as well [31]. Knipscheer \& Kleber [33] reported significant differences between migrants and non-migrants in their attitude towards psychotherapy in a Dutch sample; however, while statistically significant, the observed differences were rather small. Ditte et al. reported a less favorable attitude towards psychotherapy in Russian migrants as compared to German participants [35]. Our group found a less positive attitude towards psychotherapy in individuals of Turkish background in a previous study [34], where migration background was the most important predictor beyond sociodemographic factors. Nonetheless, the participants in the previous study were recruited in waiting rooms of general practitioners whereas the participants for the current study were already in psychiatric treatment, which may in parts explain the observed differences in the results. It can be hypothesized that patients already actively seeking psychiatric treatment in general may have a more positive attitude towards psychiatry and psychotherapy than individuals not seeking psychiatric treatment and that therefore migration background may play a smaller role in our sample than in samples from the general population. In addition, the outpatient unit from which patients were recruited for the study is specialized in treatment of migrants. The use of professional interpreters and the presence of staff with migration background may reduce feelings of stigmatization and could also contribute to a less negative view on psychotherapy in patients with migration background.

The finding that sociodemographic and clinical variables influence attitude towards psychotherapy is in line with previous studies. For example, Constantine and Gainor [39] found that individuals with higher depression symptom load were more likely to seek treatment. When correcting for education level, differences in attitude towards medication were smaller. Attitude towards treatment is generally considered to be more positive in patients with higher education levels (e.g., [27, 36]). Gender only partially predicted attitude towards psychotherapy in our analyses, which is in line with mixed findings of previous studies [33, 37, 62].

The attitude towards medication was more positive in patients of Turkish and Eastern European background. While gender, depression symptom load and current medication intake were associated with attitude towards medication in our sample, acculturation was, similar to the attitude towards psychotherapy, not a significant predictor. The more positive attitude in these two subgroups contradicts other studies which reported a less favorable attitude towards medication in ethnic minorities [43-48]. However, most of the previous studies have been conducted in the US examining individuals of Hispanic or African-American origin. One study conducted in Switzerland included mainly immigrants from Western European countries who were excluded from our analyses due to the small sample size in our sample [48]. Therefore, our result indicates cultural differences in attitude towards medication and underlines the importance in considering specific cultural factors when initiating medication in psychiatric patients with migration background. The finding that acculturation did not influence attitude towards medication beyond sociodemographic factors is in line with an earlier study in Hispanic patients [51]. However, since other studies found an impact of acculturation on medication adherence [49, 50, 52-54], which may in parts represent attitude towards medication, final conclusions cannot be drawn and more research in this field is required.

Several limitations need to be considered in interpretation of our findings. The sample was a convenience sample and not a representative data set, so the results cannot be applied to the general population. In particular, since the participants were all patients in a psychiatric outpatient unit, conclusions about reasons for migrants to not utilize psychiatric treatment cannot be drawn. In addition, the sample size of the subgroups was rather small, limiting statistical power to identify significant effects. Due to the small sample size, duration of stay in Germany and comparisons between 1st vs. 2nd migrant generation could not be incorporated in our analyses. Subgroup analyses by type of medication or psychiatric diagnose could also not be performed due to the limited sample size. Although we controlled for confounding variables in our analyses, the results may be biased due to other differences among the groups. The questions in the DAI were related to general attitude towards medication and not to psychopharmacology specifically; therefore, the attitude towards specific antidepressant or antipsychotic treatment cannot be assessed with our data. Finally, the Cronbach's alpha of the QAPT subscales and the DAI in our sample was not very high, indicating low reliability and limiting the ability to detect significant differences.

\section{Conclusions}

In summary, our study contributes to a better understanding of views on psychotherapy and medication in migrants. Since sociodemographic differences among different migrant groups and patients without migration background seem to be stronger associated with patients' views as compared to acculturation, our study underlines the need to consider these sociodemographic factors in psychiatric treatment of migrants. 


\section{Supplementary information}

Supplementary information accompanies this paper at https://doi.org/10. 1186/s12888-020-02585-1.

Additional file 1: Supplementary Tables. Tables S1-5 Results and descriptive statistics of the two analysis of covariance with the factor migration background and the Drug Attitude Inventory (DAl) as dependent variable. $R^{2}=.19^{*}$, corrected $R^{2}=.17$ (both for analysis 2). The corrections are based on the mean value of $S C L$ Somatization $M=2.41$,

$\mathrm{SCL}$ Depression $\mathrm{M}=2.83, \mathrm{SCL}$ Anxiety $\mathrm{M}=1.99$. The $\mathrm{DAl}$ value represents an arithmetic mean of a 2 point Likert scale ( $1=$ True, $2=$ False) with higher values indicating a more positive attitude. MENA = Middle East and North Africa Region, MG = migration background, DAI = Drug Attitude Inventory, SCL = Symptom Check List, SE = standard error, Sum $\mathrm{Sq}=\mathrm{Sum}$ of Squares, $\mathrm{df}=$ degrees of freedom, MSS = Mean sum of squares. Table S6. Complete results of the hierarchical Regression predicting the QUAPT scales judgment, competence, acceptance and general attitude as well as the DAI scale within the samples with Turkish, East European and MENAP background. The acculturation scales are added in the second step. School education: $0=10 w, 1=$ high, Gender: $0=$ female, $1=$ male, religious affiliation: $0=$ yes, $1=$ no. Higher scores on the scales of the QUAPT and DAI indicate a more positive attitude on that scale. For simplicity reasons the control variables are only presented in step 1. MENA = Middle East and North Africa Region, QUAPT = Questionnaire on Attitudes Toward Psychotherapeutic Treatment, DAI = Drug Attitude Inventory, $\mathrm{SCL}=$ Symptom Check List. ${ }^{*} p<.05$

\section{Abbrevations}

ANCOVA: Analysis of covariance; DAl: Drug attitude inventory; MENA: Middle East, North Africa; MENAP: Middle East, North Africa, Afghanistan/Pakistan; QAPT: Questionnaire on attitudes toward psychotherapeutic treatment; SCL14: Symptom Checklist-14

\section{Acknowledgments}

EJB participated in the Clinician Scientist Program of Charité and the Berlin Institute of Health. We acknowledge support from the German Research Foundation (DFG) and the Open Access Publication Fund of Charité Universitätsmedizin Berlin.

\section{Authors' contributions}

EJB: Study design, recruitment, data analysis, writing of manuscript. ND: recruitment, data analysis, writing of manuscript. NM: recruitment, data management. JGW: recruitment, data management. SG: recruitment, data management. HJB: study design, data analysis. MSO: study design, writing of manuscript. All authors read and approved the final manuscript.

\section{Funding}

No funding was obtained for the presented study.

\section{Availability of data and materials}

The datasets used for the current study are available from the corresponding author on reasonable request.

\section{Ethics approval and consent to participate}

The study was approved by the ethics board of Charité - Universitätsmedizin Berlin (reference number: EA4/007/15) and conducted in accordance with the Declaration of Helsinki. All participants gave written informed consent before participation in the study.

\section{Consent for publication}

Not applicable.

\section{Competing interests}

EJB: speaker fees from Servier and Medice. MSO: Speaker from Servier and Forum für medizinische Fortbildung - FomF, expert opinion for the court. JGW, ND, NM, SG and HJB declare no conflicts of interest.
Received: 12 September 2019 Accepted: 5 April 2020

Published online: 17 April 2020

\section{References}

1. Bundesamt S. Statistisches Jahrbuch 2016. Wiesbaden: Statistisches Bundesamt; 2016. 2016.

2. Aichberger MC, Bromand Z, Rapp MA, Yesil R, Montesinos AH, Temur-Erman $S$, et al. Perceived ethnic discrimination, acculturation, and psychological distress in women of Turkish origin in Germany. Soc Psychiatry Psychiatr Epidemiol. 2015;50(11):1691-700.

3. Jurado D, Alarcon RD, Martinez-Ortega JM, Mendieta-Marichal Y, GutierrezRojas L, Gurpegui M. Factors associated with psychological distress or common mental disorders in migrant populations across the world. Rev Psiquiatr Salud Ment. 2017;10(1):45-58.

4. Dapunt J, Kluge $U$, Heinz A. Risk of psychosis in refugees: a literature review. Transl Psychiatry. 2017;7(6):e1149.

5. Dingoyan D, Schulz H, Kluge U, Penka S, Vardar A, von Wolff A, et al. Lifetime prevalence of mental disorders among first and second generation individuals with Turkish migration backgrounds in Germany. BMC Psychiatry. 2017;17(1):177.

6. Tortelli A, Errazuriz A, Croudace T, Morgan C, Murray RM, Jones PB, et al. Schizophrenia and other psychotic disorders in Caribbean-born migrants and their descendants in England: systematic review and meta-analysis of incidence rates, 1950-2013. Soc Psychiatry Psychiatr Epidemiol. 2015;50(7): 1039-55.

7. Cantor-Graae E, Selten JP. Schizophrenia and migration: a meta-analysis and review. Am J Psychiatry. 2005;162(1):12-24.

8. Levecque K, Lodewyckx I, Bracke P. Psychological distress, depression and generalised anxiety in Turkish and Moroccan immigrants in Belgium: a general population study. Soc Psychiatry Psychiatr Epidemiol. 2009;44(3): 188-97.

9. Aichberger MC, Neuner B, Hapke U, Rapp MA, Schouler-Ocak M, Busch MA. Association between migrant status and depressive symptoms in the older population in Germany. Psychiatr Prax. 2012;39(3):116-21.

10. Bermejo I, Mayninger E, Kriston L, Harter M. Mental disorders in people with migration backround compared with German general population. Psychiatr Prax. 2010;37(5):225-32.

11. Crafa D, Warfa N. Maternal migration and autism risk: systematic analysis. Int Rev Psychiatry. 2015;27(1):64-71.

12. Cantor-Graae E, Pedersen CB. Full spectrum of psychiatric disorders related to foreign migration: a Danish population-based cohort study. JAMA Psychiatry. 2013;70(4):427-35.

13. Sariaslan S, Morawa E, Erim Y. Mental distress in primary care patients: German patients compared with patients of Turkish origin. Nervenarzt. 2014 85(5):589-95.

14. Bermejo I, Nicolaus L, Kriston L, Holzel L, Harter M. Culture sensitive analysis of psychosomatic complaints in migrants in Germany. Psychiatr Prax. 2012; 39(4):157-63.

15. Brandl EJ, Dietrich N, Mell N, Winkler J, Gutwinski S, Bretz J, et al. Clinical and sociodemographic Differences Between Patients with and without Migration Background in a Psychiatric Outpatient Service. Psychiatr Prax. 2018;45(7):367-74.

16. Durbin A, Moineddin R, Lin E, Steele LS, Glazier RH. Mental health service use by recent immigrants from different world regions and by nonimmigrants in Ontario, Canada: a cross-sectional study. BMC Health Serv Res. 2015;15:336.

17. Schaffer A, Cairney J, Cheung AH, Veldhuizen S, Levitt AJ. Use of treatment services and pharmacotherapy for bipolar disorder in a general populationbased mental health survey. J Clin Psychiatry. 2006;67(3):386-93.

18. Antoniades J, Mazza D, Brijnath B. Efficacy of depression treatments for immigrant patients: results from a systematic review. BMC Psychiatry. 2014; 14:176.

19. Koch E, Hartkamp N, Siefen RG, Schouler-Ocak M. German pilot study of psychiatric inpatients with histories of migration. Nervenarzt. 2008;79(3):32839.

20. Hung $\mathrm{Cl}$. Factors predicting adherence to antidepressant treatment. Curr Opin Psychiatry. 2014;27(5):344-9.

21. Wallach-Kildemoes $H$, Thomsen LT, Kriegbaum M, Petersen JH, Norredam M. Antidepressant utilization after hospitalization with depression: a comparison between non-Western immigrants and Danish-born residents BMC Psychiatry. 2014;14:77. 
22. Forcada I, Pera V, Cruz I, Pifarre J, Serna C, Rue M, et al. Comparison of immigrant and native-born population adherence to antipsychotic treatment in a Spanish health region. Community Ment Health J. 2013;49(2): 199-205.

23. Rossom RC, Shortreed S, Coleman KJ, Beck A, Waitzfelder BE, Stewart C, et al. Antidepressant adherence across diverse populations and healthcare settings. Depress Anxiety. 2016;33(8):765-74.

24. Diaz E, Woods SW, Rosenheck RA. Effects of ethnicity on psychotropic medications adherence. Community Ment Health J. 2005;41(5):521-37.

25. Schouler-Ocak M, Bretz HJ, Hauth I, Montesinos AH, Koch E, Driessen M et al. Patients of immigrant origin in outpatient psychiatric facilities: a comparion between Turkish, eastern European and German patients. Psychiatr Prax. 2010;37(8):384-90.

26. Thompson A, Hunt C, Issakidis C. Why wait? Reasons for delay and prompts to seek help for mental health problems in an Australian clinical sample. Soc Psychiatry Psychiatr Epidemiol. 2004;39(10):810-7.

27. Selkirk M, Quayle E, Rothwell N. A systematic review of factors affecting migrant attitudes towards seeking psychological help. J Health Care Poor Underserved. 2014;25(1):94-127.

28. Miller MJ, Yang M, Hui K, N. Y. M, Lim RH. A bilinear multidimensional measurement model of Asian American acculturation and enculturation: implications for counseling interventions. J Couns Psychol. 2011;58(3):34657.

29. Kim BSK. Adherence to Asian and European American cultural values and attitudes toward seeking professional psychological help among Asian American college students. J Couns Psychol. 2007;54(4):474-80.

30. Jang Y, Chiriboga DA, Okazaki S. Attitudes toward mental health services: age-group differences in Korean American adults. Aging Ment Health. 2009; 13(1):127-34.

31. Sun S, Hoyt WT, Brockberg D, Lam J, Tiwari D. Acculturation and enculturation as predictors of psychological help-seeking attitudes (HSAs) among racial and ethnic minorities: A meta-analytic investigation. J Couns Psychol. 2016;63(6):617-32.

32. Calliess IT, Schmid-Ott G, Akguel G, Jaeger B, Ziegenbein M. Attitudes towards psychotherapy of young second-generation Turkish immigrants living in Germany. Psychiatr Prax. 2007;34(7):343-8.

33. Knipscheer JW, Kleber RJ. Help-seeking behaviour regarding mental health problems of Mediterranean migrants in the Netherlands: familiarity with care, consultation attitude and use of services. Int J Soc Psychiatry. 2005; 51(4):372-82.

34. Bretz J, Sahin D, Brandl EJ, Schouler-Ocak M. Cultural Influence on Attitude towards Psychotherapy - A Comparison of Individuals of Turkish Origin with Individuals without Migration Background. Psychother Psychosom Med Psychol. 2019;69(5):176-81.

35. Ditte D, Schulz W, Schmid-Ott G. Attitude towards psychotherapy in the Russian population and in the population with a Russian/soviet cultural background in Germany. A pilot study. Nervenarzt. 2006;77(1):64-72.

36. Schmid-Ott G, Reibold S, Ernst GH, Niederauer HH, Künsebeck HW, Schulz W, Lamprecht F, et al. Development of a Questionnaire to Assess Attitudes towards Psychotherapeutic Treatment. Dermatol Psychosom. 2003;(4):18793.

37. Petrowski K, Hessel AK, A. Weidner, K., Brähler E, Hinz A. Attitudes towards psychotherapy in the general population. Psychother Psychosom Med Psychol 2014;64(2):82-85.

38. Obasi EM, Leong FTL. Psychological distress, acculturation, and mental health-seeking attitudes among people of African descent in the United States: A preliminary investigation. J Couns Psychol. 2009;56(2):227-38.

39. Constantine MG, Gainor KA. Depressive symptoms and attitudes toward counseling as predictors of biracial college Women's psychological helpseeking behavior. Women Therapy. 2004;27(1-2):147-58.

40. De Las CC, Penate W. Explaining pharmacophobia and pharmacophilia in psychiatric patients: relationship with treatment adherence. Hum Psychopharmacol. 2015;30(5):377-83.

41. De Las CC, Penate W, Cabrera C. Perceived health control: A promising step forward in our understanding of treatment adherence in psychiatric care. $J$ Clin Psychiatry. 2016;77(10):e1233-e9.

42. Kondratova L, Konig D, Mlada K, Winkler P. Correlates of negative attitudes towards medication in people with schizophrenia. Psychiatr Q. 2019;90(1): 159-69.

43. Wagner AW, Bystritsky A, Russo JE, Craske MG, Sherbourne CD, Stein MB et al. Beliefs about psychotropic medication and psychotherapy among primary care patients with anxiety disorders. Depress Anxiety. 2005;21(3):99105.

44. Cooper LA, Gonzales JJ, Gallo JJ, Rost KM, Meredith LS, Rubenstein LV, et al. The acceptability of treatment for depression among African-American, Hispanic, and white primary care patients. Med Care. 2003;41(4):479-89.

45. Dwight-Johnson M, Sherbourne CD, Liao D, Wells KB. Treatment preferences among depressed primary care patients. J Gen Intern Med. 2000;15(8):52734.

46. Hazlett-Stevens H, Craske MG, Roy-Byrne PP, Sherbourne CD, Stein MB, Bystritsky A. Predictors of willingness to consider medication and psychosocial treatment for panic disorder in primary care patients. Gen Hosp Psychiatry. 2002;24(5):316-21.

47. Givens JL, Houston TK, Van Voorhees BW, Ford DE, Cooper LA. Ethnicity and preferences for depression treatment. Gen Hosp Psychiatry. 2007;29(3):18291.

48. Thorens G, Gex-Fabry M, Zullino DF, Eytan A. Attitudes toward psychopharmacology among hospitalized patients from diverse ethnocultural backgrounds. BMC Psychiatry. 2008;8:55.

49. Denktas S, Koopmans G, Birnie E, Foets M, Bonsel G. Underutilization of prescribed drugs use among first generation elderly immigrants in the Netherlands. BMC Health Serv Res. 2010;10:176.

50. Telles C, Karno M, Mintz J, Paz G, Arias M, Tucker D, et al. Immigrant families coping with schizophrenia. Behavioral family intervention v. case management with a low-income Spanish-speaking population. $\mathrm{Br} J$ Psychiatry. 1995;167(4):473-9.

51. Cabassa L, Lester R, Zayas LH. "It's like being in a labyrinth:" Hispanic immigrants' perceptions of depression and attitudes toward treatments. J Immigr Minor Health. 2007;9(1):1-16.

52. Tailakh AK, Evangelista LS, Morisky DE, Mentes JC, Pike NA, Phillips LR. Acculturation, medication adherence, lifestyle behaviors, and blood pressure control among Arab Americans. J Transcult Nurs. 2016;27(1):57-64.

53. Foster BA, Read D, Bethell C. An analysis of the association between parental acculturation and children's medication use. Pediatrics. 2009;124(4): 1152-61.

54. Padilla R, Steiner JF, Havranek EP, Beaty B, Davidson AJ, Bull S. A comparison of different measures of acculturation with cardiovascular risk factors in Latinos with hypertension. J Immigr Minor Health. 2011;13(2):284-92.

55. Harfst T, Koch U, Kurtz von Aschoff C, Nutzinger DO, Rüddel H, Schulz H. Development and validation of a short version of the symptom Checklist90-R. DRV-Schriften. 2002;33:71-3.

56. Hamidi S, Akinci F. Measuring efficiency of health Systems of the Middle East and North Africa (MENA) region using Stchastic frontier analysis. Appl Health Econ Health Policy. 2016;14(3):337-47.

57. Schulz W, Shin MA, Schmid-Ott G. Attitudes towards psychotherapy in South Korea and Germany : A cross-cultural comparative study. Nervenarzt. 2018;89(1):51-7.

58. Hogan TP, Awad AG, Eastwood R. A self-report scale predictive of drug compliance in schizophrenics: reliability and discriminative validity. Psychol Med. 1983;13(1):177-83.

59. Townsend L, Floersch J, Findling RL. Adolescent attitudes toward psychiatric medication: the utility of the drug attitude inventory. J Child Psychol Psychiatry. 2009;50(12):1523-31.

60. Ward C, Rana-Deuba A. Acculturation and adaptation revisited. J Cross-Cult Psychol. 1999;30(4):422-42.

61. Ward C, Kennedy A. Acculturation strategies, psychological adjustment, and sociocultural competence during cross-cultural transitions. Int J Intercult Relat. 1994;18(3):329-43.

62. Mackenzie CS, Scott T, Mather A, Sareen J. Older adults'help-seeking attitudes and treatment beliefs concerning mental health problems. Am J Geriatr Psychiatry. 2008;16(12):1010-9.

\section{Publisher's Note}

Springer Nature remains neutral with regard to jurisdictional claims in published maps and institutional affiliations. 